\title{
Thermo-mechanical behavior and fatigue strength of a grey cast iron for automotive brake discs considering graphite flakes debonding
}

\author{
Louis Augustins ${ }^{1,2, a}$, François Hild ${ }^{1}$ and René Billardon ${ }^{1,3}$ \\ ${ }^{1}$ LMT Cachan, 61 avenue du Président Wilson, 94230 Cachan, France \\ ${ }^{2}$ PSA Peugeot Citroën, Route de Gisy, 78943 Vélizy-Villacoublay Cedex, France \\ ${ }^{3}$ Messier-Bugatti-Dowty, Inovel Parc Sud, 78140 Vélizy-Villacoublay, France
}

\begin{abstract}
This paper aims at developing an approach for thermo-mechanical fatigue design of automotive brake discs made of lamellar graphite (grey) cast-iron. The first step consists of modelling the nonlinear cyclic behavior and tension/compression strong dissymmetry of grey cast iron. The proposed model is based on the introduction of a second-order induced damage tensor. From the analysis of the damage mechanisms, a fatigue criterion based on the dissipated energy per cycle is proposed.
\end{abstract}

\section{Introduction}

The issue of the present work is to develop a method for thermo-mechanical fatigue design of automotive brake discs. The occurrence of cracks in brake discs is commonly associated to thermal gradients; surface gradients for crack network [1] on the frictional surface but also thermal gradient between the ring and the bowl [2], leading to crack initiation in the groove, on which is focused the present study.

To perform a low cycle fatigue analysis, a constitutive model accurately representing the behavior of the material under cyclic loading and a predictive fatigue criterion have to be defined. The specificity of grey cast iron is the shape taken by the free carbon, which is in the form of graphite flakes uniformly distributed in a pearlitic matrix. Under tensile loading, these flakes behave as microcracks, leading to a non-linear behavior in tension at low strain values, and a very strong tension/compression dissymmetry. Under cyclic loading, elastic-viscoplastic constitutive laws commonly used do not allow the material response to be accurately described, due to this strong dissymmetry. Several authors have tried to treat this phenomenon by using an asymmetric yield surface [3-6], but these approaches do not permit to simulate neither the important loss of stiffness nor the closure of debonded flakes.

\footnotetext{
${ }^{a}$ Corresponding author: louis . augustins@mpsa.com
}

This is an Open Access article distributed under the terms of the Creative Commons Attribution License 4.0, which permits unrestricted use, distribution, and reproduction in any medium, provided the original work is properly cited. 


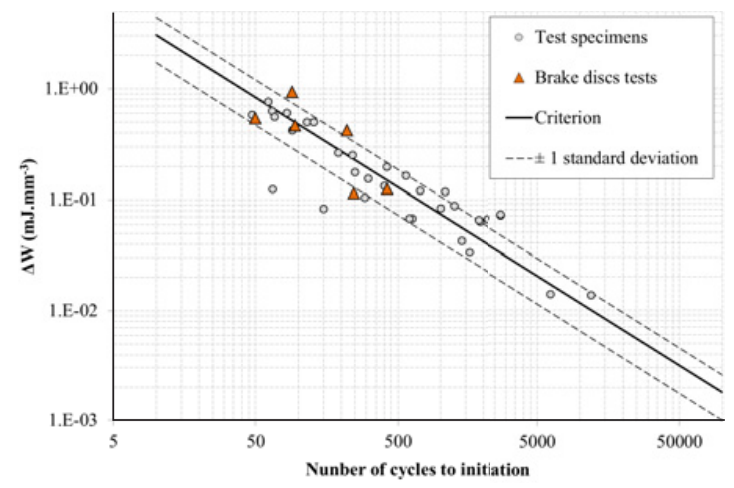

Figure 1. LCF criterion: experimental results on test specimens and calculated dissipated energy on structures.

\section{Constitutive model and fatigue strength}

We first consider the case of monotonic loadings, where flakes are either closed in compression or opened in tension. Based on the concept of effective stress [7], an elastic-viscoplastic constitutive model taking into account the flakes/matrix debonding, using a second-order induced damage tensor [8], has been developed. The behavior of the matrix is modelled with two kinematic hardenings, one non-linear and one linear, and a classical Norton law [7] is used to describe viscosity. Such a model can precisely represent the non-linearity in tension and compression and the loss of stiffness but it cannot describe the closure of debonded flakes for complex loadings.

In the case of a tension/compression loading, microcracks opening and closure conditions have been identified. A rheological model, based on two branches - one representing the damaged matrix affected by a factor $(1-D)$ and the other its complementary part (the crack) affected by $D$ - has been implemented. It uses the previous 3D model for the matrix branch and a 1D description for the complementary part, which can be deactivated when the flakes are open. The model enables a very good description of the cyclic behaviour.

The generalization to the case of multiaxial loadings required some assumptions (damage deactivation), and the model has been implemented as an Abaqus UMAT procedure, and then used for finite element thermo-mechanical simulations of brake discs.

Uniaxial fatigue tests and post mortem SEM observations were conducted and damage mechanisms were analysed. A fatigue life criterion using the dissipated energy $(\Delta \mathrm{W})$ per stabilized cycle [9] has been identified. Brake discs tests on a specific dynamometric bench were also conducted at PSA Peugeot Citroën, allowing the number of braking cycles before crack initiation in the groove to be defined. The numerical simulations of these braking conditions were realised with the described constitutive model. The identified fatigue criterion has resulted to conclusive correlations between the experimental and predicted number of cycles before crack initiation (see Fig. 1).

\section{References}

[1] G. Degallaix, P. Dufrénoy, European Structural Integrity Society 29, 167 (2002)

[2] F. Vallet, Etude de la fissuration d'un disque de frein à partir de l'analyse de son comportement thermomécanique. (Doctoral Thesis, 1999)

[3] N. Manilin, O. Batanova, Izv. VUZov Mashinostroenie 12, 9 (1979)

[4] H E. Hjelm, Trans. ASME 116, 148 (1994)

[5] H. Altenbach, G. B. Stoychev, K. N. Tushtev, Int. J. Plasticity 17, 719 (2001) 
[6] P. C. Brooks, D. C. Barton, S. Koetniyom, Proceedings of the Institution of Mechanical Engineers, Part D : Journal of Automobile Engineering 216, 349 (2002)

[7] J. Lemaitre, J.-L. Chaboche, Mécanique des Matériaux Solides, deuxième édition (Dunod, Cachan, 1996)

[8] C. Denoual, Approche probabiliste du comportement à l'impact du carbure de silicium : application aux blindages moyens. (Doctoral Thesis, 1998)

[9] E. Charkaluk, A. Constantinescu, Proceedings of the $6^{\text {th }}$ European Conference on braking (JEF2010), 335 (2010) 